\title{
Systematic Review and Meta-Analysis of Prone Position on Intraocular Pressure in Adults Undergoing Surgery
}

\author{
SHARON ANN VAN WICKLIN, PHD, RN, CNOR, CRNFA(E), CPSN-R, PLNC, FAAN, ISPAN-F \\ Aurora, Colorado
}

\begin{abstract}
Background: Patients undergoing surgery in the prone position may be at risk for postoperative vision loss associated with increased intraocular pressure. The purpose of this systematic review and meta-analysis is to estimate the magnitude of the increase in intraocular pressure at specific perioperative time points in adult patients. The research question to be addressed is "What is the magnitude of the increase in intraocular pressure at specific perioperative time points in adults undergoing surgery in the prone position?"

Methods: Comprehensive search strategies were used to identify nine eligible studies $(\mathrm{N}=229)$. Standardized mean difference effect sizes were calculated for two intraoperative time points.

Time points for meta-analysis were selected to achieve the greatest number of comparisons for analysis at each time point. Prediction intervals for each time point were also calculated to show the dispersion of true effect sizes around the mean.

Results: Meta-analysis showed that intraocular pressure increased significantly between induction of anesthesia and up to 10 minutes of prone position (T1: standardized mean difference $[d]=2.55 ; P<.001)$ and continued to increase significantly until the end of the prone position (T2: $d=3.44 ; P=.002)$.

Conclusions: Intraocular pressure increases of this magnitude demonstrate the need for implementing interventions to reduce the risk for postoperative vision loss in patients undergoing surgery in the prone position.

Clinical Relevance: Implementing preoperative ophthalmologic examinations for patients undergoing surgery in the prone position may help to reduce the risk for ocular injury. Intraoperative interventions that can be implemented to reduce or mitigate the increase in intraocular pressure include implementing a 5- to 10-degree reverse Trendelenburg prone position, reducing the amount of time the patient is in the prone position, considering staged procedures, monitoring intraocular pressure, providing periodic position changes or rest periods, preventing pressure on the eye, and administering specific medications or anesthetics.
\end{abstract}

Complications

Keywords: intraocular pressure, prone position, ischemic optic neuropathy, central retinal artery occlusion

\section{INTRODUCTION}

In the prone position, the patient is positioned face-down on their abdomen. This position provides surgical access to the dorsal aspects of the patient's body. There are ocular complications associated with the prone position. Postoperative vision loss, which may be partial or complete and unilateral or bilateral, is a serious complication of surgery in the prone position, and it occurs with greater frequency after spine, head and neck, and some orthopedic procedures. ${ }^{1,2}$ Following surgery in the prone position, there have been reports of postoperative vision loss associated with increased intraocular pressure (IOP), ${ }^{3-20}$ as well as reports of chemosis, ${ }^{20}$ subconjunctival hemorrhage, ${ }^{21}$ ocular or subperiosteal orbital hemorrhage, ${ }^{22-24}$ orbital compartment syndrome, ${ }^{24,25}$ acute angle-closure glaucoma, ${ }^{26,27}$ and Horner syndrome. ${ }^{28}$

When the patient is in the prone position, IOP increases and the extent of this increase is related to the amount of time the patient is in the prone position. $^{25,29-34}$ After only a few minutes in the prone position, IOP can increase significantly. ${ }^{35}$ According to the American Academy of Ophthalmology, ${ }^{36}$ normal IOP is 10 to $21 \mathrm{~mm} \mathrm{Hg}$. Intraocular pressures higher than $21 \mathrm{~mm} \mathrm{Hg}$ pose a risk for glaucoma, detached retina, and postoperative vision loss. ${ }^{1,2,37}$

\section{Pathogenesis of Postoperative Vision Loss}

Postoperative vision loss in patients undergoing surgery in the prone position is generally related to 1 
of 2 causes: ischemic optic neuropathy or central retinal artery occlusion. ${ }^{25,38}$

\section{Ischemic Optic Neuropathy}

Ischemic optic neuropathy is the most common cause of postoperative vision loss. ${ }^{25,38-40}$ According to the American Academy of Ophthalmology, ${ }^{41}$ ischemic optic neuropathy is caused by insufficient blood flow to the optic nerve. Ischemic optic neuropathy may present as anterior (involving ischemia and infarction of the intraocular optic nerve) or posterior (involving ischemia and infarction of the intraorbital optic nerve).$^{25}$ Although the phenomenon of ischemic optic neuropathy is not well understood, it is known that elevated IOP can lead to optic nerve injury and decreased ocular perfusion pressure. ${ }^{25,39,40}$ Perfusion pressure is the difference between pressures of the ciliary arteries in the optic nerve and the venous drainage of the eye. ${ }^{42}$ This difference is approximated by the level of IOP. The "higher the intraocular pressure, the lower the perfusion pressure, and consequently, the lower the blood flow in the optic nerve head." ${ }^{2(p}$ 608) The lower the blood flow in the optic nerve head, the greater the risk for ischemic optic neuropathy and postoperative vision loss. The ischemic process can occur as a direct result of decreased blood supply from the arteries of the optic nerve or by venous stasis that occurs as a result of decreased venous outflow and a compartment syndrome of the optic nerve or optic canal. ${ }^{25,39,43}$ The subsequent postoperative vision loss can range from temporary blurring to partial to complete blindness; however, once a loss of vision occurs, it is almost always an irreversible complication. ${ }^{1,2}$

\section{Central Retinal Artery Occlusion}

Central retinal artery occlusion is most often caused by pressure on the eye from the prone position, and especially by positioning the patient's head on a prominent headrest. Pressure on the eye increases IOP and decreases blood flow to the retina through the central retinal artery. ${ }^{25,38,44}$ The increased IOP exceeds the profusion pressure of the central retinal artery, leading to ischemia of the retina. ${ }^{38}$ Most patients with central retinal artery occlusion are left with a unilateral, permanent blindness. ${ }^{38,44}$

\section{Risk Factors for Postoperative Vision Loss}

Numerous risk factors for postoperative vision loss have been identified that include older patients with elevated baseline IOPs; patients with existing hypertension, diabetes, obesity, anemia, vascular disease, increased blood viscosity; and patients who smoke, as well as patients who experience intraoperative hypotension, blood transfusion, lower colloid use during fluid administration, or prolonged surgical times, and patients who are positioned on horseshoe-shaped headrests. ${ }^{25,38,45,46}$ Patients who are predisposed to acute angle-closure glaucoma are also at high risk for ocular injury even during short procedures because the prone position can shift the lens-iris diaphragm forward so it obstructs aqueous humor outflow and increases IOP. ${ }^{20}$

\section{Incidence of Postoperative Vision Loss}

The exact incidence of postoperative vision loss is unknown because the data come largely from retrospective studies and case reports. ${ }^{2,47}$ The incidence of postoperative vision loss following nonocular surgery has been estimated to be as low as $0.0002 \%$ and as high as $0.2 \%{ }^{48}$ In a retrospective cohort study using the National Inpatient Sample, the largest inpatient database in the United States, Patil et al ${ }^{47}$ examined the records of 4728815 patients who underwent spinal procedures between 1993 and 2002. The researchers found that 4134 patients $(0.09 \%)$ developed postoperative visual impairment. An additional 271 patients $(0.006 \%)$ had ischemic optic neuropathy, and an additional 47 patients $(0.001 \%)$ had central retinal artery occlusion. In a 10-year prevalence study of postoperative vision loss in the United States, Shen et $a 1^{49}$ reviewed data from more than 5.6 million patients included in the Nationwide Inpatient Sample from 1995 to 2005. The researchers found the incidence of postoperative vision loss for patients undergoing laminectomy without fusion was 0.86 per $10000(0.009 \%)$. For patients undergoing spinal fusion, the incidence was 3.09 per $10000(0.03 \%)$ for all fusions, 0.66 per $10000(0.007 \%)$ fusions with anterior approach, and 5.50 per $10000(0.06 \%)$ fusions with posterior approach.

\section{Purpose}

Although some researchers have studied the quantitative increase of IOP in surgical patients in the prone position, ${ }^{1,2,14,16,17,34,50}$ there is a need for systematic review and meta-analyses of these studies to demonstrate the overall effect size and provide high-quality evidence supporting, or negating, the 
need for implementing interventions to mitigate the increase of IOP and reduce the risk for postoperative vision loss. Meta-analysis research methods provide increased power compared to individual studies, improve estimates of effect size, and help resolve uncertainty when the results of individual studies disagree. ${ }^{51}$ Because all of the evidence pertaining to a particular phenomenon is included in the analysis, meta-analysis research provides a high level of objectivity, precision, and generalizability. ${ }^{52}$

Currently, there has been no quantitative metaanalytic synthesis of the existing studies examining the increase in IOP in adult patients undergoing surgery in the prone position. The purpose of this systematic review and meta-analysis is to estimate the magnitude of the increase in IOP at selected perioperative time points in adult patients (ie, individuals 18 years and older) undergoing any type of surgery in the prone position. The research question to be addressed by this systematic review and meta-analysis is "What is the magnitude of the increase in IOP at specific perioperative time points in adults undergoing surgery in the prone position?"

\section{MATERIALS AND METHODS}

To ensure rigorous and transparent presentation of the methods and results of this systematic review and meta-analysis, the Preferred Reporting Items for Systematic reviews and Meta-Analyses guidelines ${ }^{53}$ have been followed.

\section{Search Strategies}

An expert health sciences reference librarian was consulted to identify the most appropriate search terms and databases for an exhaustive and varied literature search. Keywords or medical subject headings included intraocular pressure or ocular tension, and prone position. Search strategies included

- online searching of the PubMed, Cumulative Index of Nursing and Allied Health Literature, and Scopus databases, and the Cochrane Database of Systematic Reviews for published and unpublished literature;

- ancestry searching of reference lists from relevant reports to locate additional applicable references;

- author searching of individuals identified in the literature as experts in the field; and a
- dissertation search of the ProQuest database.

The author reviewed report abstracts for eligibility and obtained full-text copies of all potentially eligible reports.

\section{Inclusion and Exclusion Criteria}

Criteria for inclusion in the meta-analysis were reports written in English; published or unpublished reports of primary studies that encompassed dissertations, conference abstracts, and presentations; studies that used either a one-group, pretestposttest design or a multiple-group, pretest-posttest design; reports where the minimum age of the study participants was 18 years or older; studies that included a specific measured outcome of IOP using any type of tonometer; studies where the participants received any type of general or spinal anesthesia; and reports of studies that included sufficient data to calculate an effect size. When reports did not include sufficient data to calculate an effect size, the author contacted the researchers and statisticians on at least 2 separate occasions 2 to 3 weeks apart to obtain missing data.

Reports were excluded if the IOP was measured in adults not undergoing surgery. Reports were also excluded if data from only 1 time point of IOP measurement were present. Participant groups were additionally excluded if they were receiving an intervention specifically intended to mitigate IOP; however, participant groups representing control arms receiving placebos or no interventions were included in the systematic review and metaanalysis.

\section{Risk of Bias Within Individual Studies}

To assess the risk of bias within individual studies, the author and an experienced evidence reviewer independently evaluated and critically appraised each study for its level of strength and quality using the Association of periOperative Registered Nurses Research Evidence Appraisal Tool - Study. ${ }^{54}$ Measures such as sample size, generalizability, bias, reliability, and validity were assessed to determine whether the study quality was high, good, or low. The author and evidence reviewer participated in conference calls to discuss their independent appraisals until 100\% consensus was achieved on study design and quality levels for each of the included studies. 


\section{Risk of Bias Across Studies}

To avoid bias due to a narrow or limited search, a comprehensive and diverse literature search was conducted. Only research studies were included in the systematic review and meta-analysis to ensure the included studies were of sufficient strength and quality. As well, studies that included objective measurements of IOP at fewer than 2 or more perioperative time points were excluded. An analysis of publication bias was also conducted to determine whether unpublished research was unintentionally excluded.

\section{Coding and Data Extraction}

The author coded eligible studies and extracted the necessary data to address the research question. Effect-size data for each of the reports included in the systematic review and meta-analysis were independently coded by a trained researcher. The author and independent researcher discussed coding discrepancies for each of the eligible studies until $100 \%$ consensus was achieved.

Data related to study characteristics and study design were collected from each of the included studies. Data related to participant and surgery characteristics were collected when available. Data necessary to calculate effect sizes for all time points recorded by the researchers during the perioperative phases of the procedures included in their studies were also collected.

\section{Statistical Analyses}

Meta-analyses were conducted using Comprehensive Meta-Analysis software, version 3. ${ }^{55}$ To achieve the greatest number of comparisons for analysis at each time point and to allow for similarity with the order of events as they traditionally occur during surgery, time points for meta-analysis were selected from time points recorded by the researchers. Analyses were conducted for the following time points:

$\mathrm{T} 1$, after induction of anesthesia to 0 to 10 minutes of prone position, and

T2, 0 to 10 minutes of prone position to the end of prone position.

Standardized mean difference effect sizes were calculated for each participant group and each measured time point. $^{56}$
Effect-size values were weighted by the inverse of the variance to account for sample size and adjust for bias. Because heterogeneity was observed among study designs, sample attributes, and outcome measures, and to account for between- and withinstudy variation, a random effects model was selected a priori to synthesize effect sizes. Using a random effects model assumes that the true effect size varies from one study to the next. ${ }^{57(\mathrm{p} \text { 77) }}$ Effect sizes were interpreted as per Cohen ${ }^{56}$ with 0.2 considered a small effect size, 0.5 considered a medium effect size, and 0.8 or greater considered a large effect size. The calculated effect sizes were converted to the metric used to measure IOP (ie, $\mathrm{mm} \mathrm{Hg}$ ) using the procedures described by Lipsey and Wilson ${ }^{58}$ to facilitate interpretation of effect-size findings.

\section{Publication Bias}

A funnel plot was constructed to assess the extent of publication bias for the meta-analysis. Notably, a funnel plot may suggest publication bias, but does not eliminate the bias. ${ }^{59}$ A minimum of 3 studies is necessary in order to create a funnel plot. ${ }^{55}$ Asymmetry of the funnel plot was measured by conducting an Egger test. ${ }^{55,60,61}$ When there are less than 10 studies included in the meta-analysis, an Egger test is not advised because the power of the test may be too low to distinguish true asymmetry from chance. ${ }^{61}$ For this reason, a funnel plot was constructed and an Egger test was conducted only when the analysis included 10 or more participant groups (T1). The Orwin fail-safe $\mathrm{N}$ test was conducted when the Egger test was significant, to estimate the number of missing studies required to overturn the conclusions of the meta-analysis. ${ }^{59,62}$ The Orwin fail-safe $\mathrm{N}$ assesses the impact of publication bias to determine whether the overall observed effect is robust. ${ }^{59,62}$

\section{Heterogeneity}

The studies included in the meta-analysis were assessed for heterogeneity after deciding on the model and calculating effect sizes. Heterogeneity is any kind of variability among the studies included in a meta-analysis. $^{63}$ Heterogeneity testing explores whether the same effect is being evaluated by all studies (ie, the null hypothesis). ${ }^{64}$ The Cochrane Q, which estimates statistical significance; $\tau^{2}$, which estimates the absolute value of the true variance between studies, but not the proportion of the variance; and $I^{2}$, which estimates the proportion of 


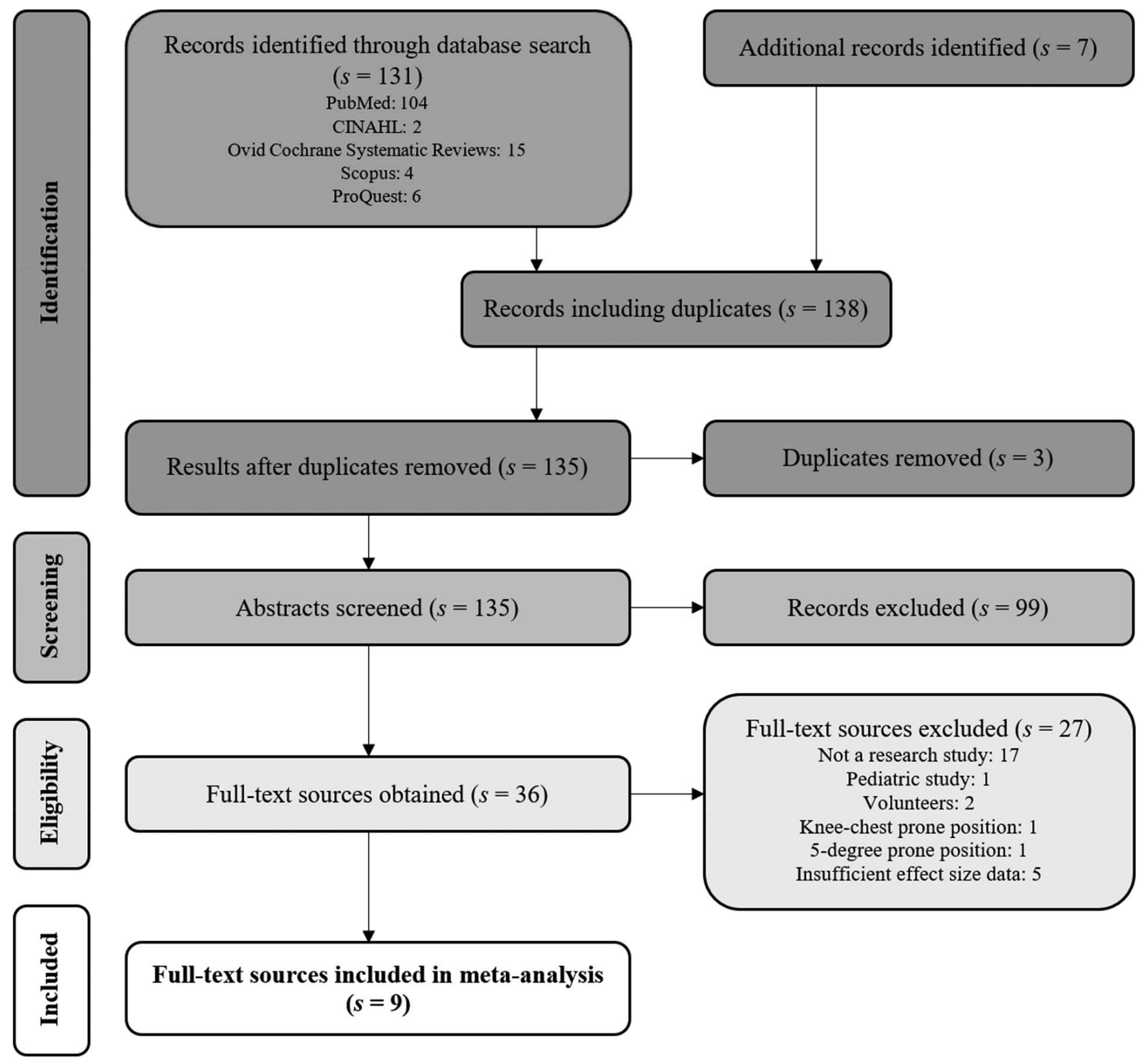

Figure 1. Flow diagram of study selection; $s$ indicates studies. Adapted from Moher D, Liberati A, Tetzlaff J, Altman DG, PRISMA Group. Preferred Reporting Items for Systematic Reviews and Meta-Analyses: The PRISMA Statement. PLoS Med. 2009;6(6):e1000097. ${ }^{53}$

true variance, but not the absolute value of the variance, were all used to test homogeneity of variance among effect sizes. ${ }^{65}$ To show the dispersion of true effect sizes around the mean, prediction intervals for each time point were also calculated. ${ }^{66}$

\section{RESULTS}

The flow of study selection is depicted in Figure 1. In total, 135 records were identified for possible inclusion, and of these, 9 studies were included in the systematic review and meta-analysis. Four studies had multiple participant groups ${ }^{67-70}$ resulting in a total of 14 participant groups and 229 participants for analysis. Table 1 contains a summary of the studies included in this review and meta-analysis.

\section{Study Characteristics}

All of the studies included in the systematic review and meta-analysis were obtained from peerreviewed journals. The researchers of 3 studies $(33.3 \%)$ reported receiving some type of funding or donated supplies. ${ }^{2,69,70}$ Although the literature 
Table 1. Summary of studies included in the systematic review and meta-analysis $(s=18 ; \mathrm{N}=229)$.

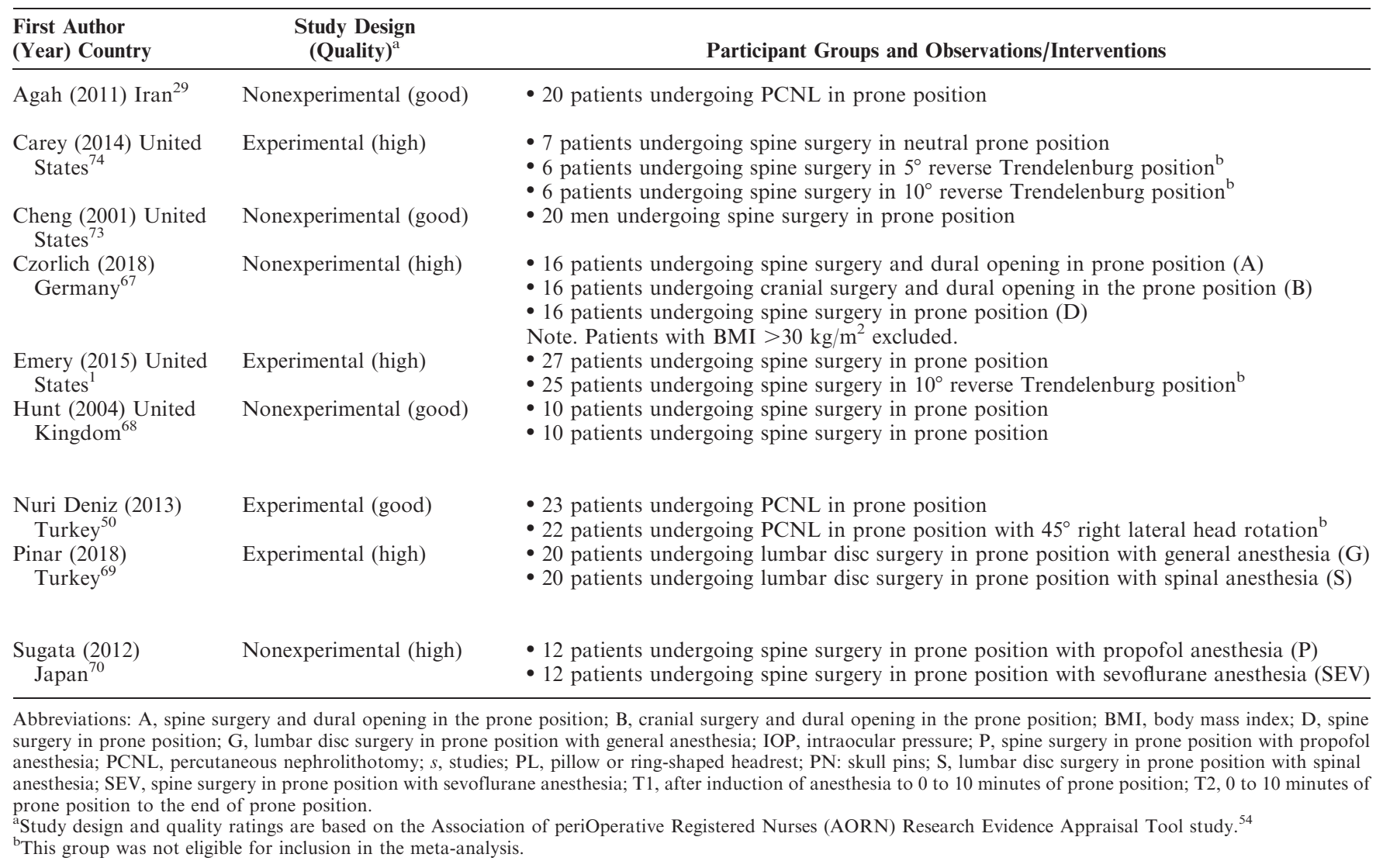

was searched without any date restriction, all of the studies included in the systematic review and metaanalysis were published between 2001 and 2018. The greatest number of studies were published in 2018 (studies $[s]=2$ ) with the greatest number of participants also occurring in $2018(\mathrm{n}=88) .{ }^{67-69}$

\section{Participant and Surgery Characteristics}

Participant and surgery characteristics are shown in Table 2. The mean (SD) age of the participants was 53.2 (8.1) years and ranged from 43.3 to 69 years. The majority of the participants were men (n $=122 ; 55.0 \%$ ). Participant race and socioeconomic status were not reported by any of the researchers. Participants ranged between having a healthy weight to being slightly overweight ${ }^{71}(22.5-27.7 \mathrm{~kg} /$ $\mathrm{m} 2$ ) with a mean (SD) body mass index (BMI) of 24.9 (1.6) $\mathrm{kg} / \mathrm{m}^{2}$. The American Society of Anesthesiologists (ASA) physical classification status ${ }^{72}$ was reported cumulatively as class I (ie, healthy), class II (ie, with mild systemic disease), or class III (ie, with severe systemic disease) by the researchers of 4 reports $(\mathrm{n}=130){ }^{29,50,69,73}$ Sugata et $\mathrm{al}^{70}$ reported patient comorbidities for diabetes $(n=5$ of $24 ; 20.8 \%$ ), and hypertension ( $\mathrm{n}=9$ of 24 ; $37.5 \%$ ).

The majority of the participants underwent spine surgery $(\mathrm{n}=170 ; 74.2 \%)$. Other participants underwent percutaneous nephrolithotomy $(\mathrm{n}=43$; $18.8 \%)$ or cranial surgery $(\mathrm{n}=16 ; 7 \%)$. The vast majority of participants $(n=222 ; 97 \%)$ received general anesthesia by inhalation $(\mathrm{n}=115 ; 51.8 \%)$, intravenous propofol $(\mathrm{n}=60 ; 27 \%)$, or unspecified methods $(\mathrm{n}=27 ; 12.2 \%)$, or received spinal anesthesia $(n=20 ; 9 \%)$. As shown in Table 2 , the mean (SD) duration of surgery was 156.0 (24.2) minutes with a range of 120 to 181 minutes. Several researchers reported the duration of prone position as a significant contributing factor between increasing IOP and prone position ${ }^{1,29,67,74}$; however, 2 researchers reported the relationship between duration of the position and increased IOP was not significant. ${ }^{68,69}$ The mean (SD) estimated blood loss was 330.1 (222.1) $\mathrm{mL}$ with a range of 120 to $615 \mathrm{~mL}$.

\section{Study Design Characteristics}

The Tono-Pen XL was the most frequently used device to measure eye pressure ${ }^{1,29,67,68,70,73,74}(s=7$; 


\begin{tabular}{|c|c|c|}
\hline IOP Measures (Tonometer) [Head Positioning] & Outcome Measures & $\begin{array}{l}\text { Effect Sizes } \\
(\text { Cohen } d)\end{array}$ \\
\hline $\begin{array}{l}\text { Measurement of IOP at } 5 \text { different time points (Tono-Pen XL) [ring- } \\
\text { shaped headrest] }\end{array}$ & Differences in IOP levels at each time point & $\begin{array}{l}\text { T1: } 11.34 \\
\text { T2: } 10.5\end{array}$ \\
\hline $\begin{array}{l}\text { Measurement of IOP at } 5 \text { different time points (Tono-Pen XL) } \\
\text { [horseshoe-shaped headrest] }\end{array}$ & Differences in IOP levels at each time point & \\
\hline $\begin{array}{l}\text { Measurement of IOP at } 5 \text { different time points (Tono-Pen XL) [skull } \\
\text { pins] }\end{array}$ & Differences in IOP levels at each time point & \\
\hline $\begin{array}{l}\text { Measurement of IOP at } 7 \text { different time points (Tono-Pen XL) [skull } \\
\text { clamp] }\end{array}$ & Differences in IOP levels at each time point & $\begin{array}{l}\text { T1 A: } 2.48 \\
\text { T1 B: } 3.44 \\
\text { T1 D: } 2.32\end{array}$ \\
\hline $\begin{array}{l}\text { Measurement of IOP at } 6 \text { to } 19 \text { different time points (Tono-Pen XL) } \\
\text { [tong traction] }\end{array}$ & Differences in IOP levels at each time point & T1: 1.97 \\
\hline $\begin{array}{l}\text { Measurement of IOP at } 3 \text { different time points (Tono-Pen XL) [PL: } \\
\text { pillow or ring-shaped headrest PN: skull pins] }\end{array}$ & Differences in IOP levels at each time point & $\begin{array}{l}\text { T1 PL: } 1.28 \\
\text { T1 PN: } 1.08 \\
\text { T2 PL: } 0.58 \\
\text { T2 PN: } 0.5\end{array}$ \\
\hline $\begin{array}{l}\text { Measurement of IOP at two different time points (Perkins MK2) } \\
\text { [silicone headrest] }\end{array}$ & Differences in IOP levels at each time point & \\
\hline $\begin{array}{l}\text { Measurements of IOP at } 4 \text { different time points (Tono-Pen AVIA) } \\
\text { [horseshoe-shaped headrest] }\end{array}$ & Differences in IOP levels at each time point & $\begin{array}{l}\text { T1 G: } 0.52 \\
\text { T1 S: } 0.39 \\
\text { T2 G: } 3.9 \\
\text { T2 S: } 2.98\end{array}$ \\
\hline $\begin{array}{l}\text { Measurements of IOP at } 5 \text { different time points (Tono-Pen XL) } \\
\text { [horseshoe-shaped headrest] }\end{array}$ & Differences in IOP levels at each time point & $\begin{array}{l}\text { T1 P: } 3.01 \\
\text { T1 SEV: } 3.61\end{array}$ \\
\hline
\end{tabular}

$\mathrm{n}=166$ ). The most frequently used method for positioning the patient's head was skull pins or clamps $(\mathrm{n}=105 ; 45.9 \%)$. Other methods included a horseshoe-shaped headrest $(\mathrm{n}=71 ; 31 \%)$, a pillow or viscoelastic gel ring-shaped headrest $(n=30$; $13.1 \%)$, or a silicone headrest $(n=23 ; 10 \%)$. Two researchers reported having 88 participants undergo preoperative ophthalmologic examinations. ${ }^{68,70}$ One

Table 2. Participant and surgery characteristics $(s=9 ; N=229)$.

\begin{tabular}{|c|c|c|}
\hline Category & $\begin{array}{c}\text { No. of } \\
\text { Participants } \\
\text { (No. of Studies) }\end{array}$ & $\begin{array}{c}\text { Mean } \pm \text { SD } \\
\text { (Range) or Percentage }\end{array}$ \\
\hline Age, y & $222(8)$ & $53.2 \pm 8.1(43.3-69)$ \\
\hline Sex & $222(8)$ & \\
\hline Women & 100 & $45.0 \%$ \\
\hline Men & 122 & $55.0 \%$ \\
\hline BMI, $\mathrm{kg} / \mathrm{m}^{2}$ & $155(5)$ & $24.9 \pm 1.6(22.5-27.7)$ \\
\hline ASA class I, II, or III & $130(5)$ & $100 \%$ \\
\hline Surgery type & $229(9)$ & \\
\hline Cranial & 16 & $7.0 \%$ \\
\hline $\begin{array}{l}\text { Percutaneous } \\
\text { nephrolithotomy }\end{array}$ & 43 & $18.8 \%$ \\
\hline Spine & 170 & $74.2 \%$ \\
\hline Anesthesia & $222(8)$ & \\
\hline General,inhalation & 115 & $51.8 \%$ \\
\hline General, propofol & 60 & $27.0 \%$ \\
\hline General, unspecified & 27 & $12.2 \%$ \\
\hline Spinal & 20 & $9.0 \%$ \\
\hline \multicolumn{3}{|l|}{ Duration, min } \\
\hline Anesthesia & $24(1)$ & $247.0 \pm 9.9(240-254)$ \\
\hline Prone position & $44(2)$ & $161.6 \pm 70.9(80-203)$ \\
\hline Surgery & $74(4)$ & $156.0 \pm 24.2(120-181)$ \\
\hline Estimated blood loss, $\mathrm{mL}$ & $95(3)$ & $330.1 \pm 222.1(120-615)$ \\
\hline
\end{tabular}

Abbreviations: ASA, American Society of Anesthesiologists Physical Classification Status; BMI, body mass index; $s$, studies. researcher reported having 48 participants undergo postoperative ophthalmologic examinations. ${ }^{68}$

\section{Effect Sizes}

Results of the meta-analysis for each time point are shown in Table 3. A graphical representation of the magnitude of changes in IOP and upper prediction intervals for induction of anesthesia (T0) through T2 is shown in Figure 2. In total, between induction of anesthesia and the end of prone position, IOP increases significantly by 17.6 $\mathrm{mm} \mathrm{Hg}$ (ie, $7.5 \mathrm{~mm} \mathrm{Hg}+10.1 \mathrm{~mm} \mathrm{Hg}=17.6 \mathrm{~mm}$ $\mathrm{Hg}$ ). Based on the upper limits of the prediction intervals, in $95 \%$ of all populations, IOP could increase by as much as $57.8 \mathrm{~mm} \mathrm{Hg}$ (ie, $19.8 \mathrm{~mm} \mathrm{Hg}$ $+38.0 \mathrm{~mm} \mathrm{Hg}=57.8 \mathrm{~mm} \mathrm{Hg}$ ). The IOP increases significantly after the patient is placed into the prone position ( $\mathrm{T} 1:+7.5 \mathrm{~mm} \mathrm{Hg}$ ) and continues to increase significantly while the patient is in the prone position $(\mathrm{T} 2:+10.1 \mathrm{~mm} \mathrm{Hg})$. The forest plots of effect sizes for each participant group included in the meta-analysis for $\mathrm{T} 1$ and $\mathrm{T} 2$ are shown in Figures 3 and 4, respectively. The funnel plot for publication bias for $\mathrm{T} 1$ is shown in Figure 5.

\section{Postoperative Complications}

None of the researchers reported transient or permanent vision loss as a result of increased IOP. Carey et $\mathrm{al}^{74}$ reported 1 corneal abrasion requiring 
Table 3. Effect sizes and magnitude of change in IOP for T1 through T2 $(s=9 ; \mathrm{N}=229)$.

\begin{tabular}{|c|c|c|c|c|c|c|c|c|c|c|c|}
\hline \multirow{2}{*}{$\begin{array}{l}\text { Time } \\
\text { Points }\end{array}$} & \multirow[b]{2}{*}{$s$} & \multirow[b]{2}{*}{$k$} & \multirow[b]{2}{*}{$\mathbf{n}$} & \multirow[b]{2}{*}{ Model } & \multirow[b]{2}{*}{ c } & \multicolumn{2}{|c|}{$95 \%$ CI } & \multirow[b]{2}{*}{ Q } & \multirow[b]{2}{*}{$I^{2}$} & \multirow[b]{2}{*}{ Mean Change in IOP } & \multirow[b]{2}{*}{ Prediction Interval $^{\mathbf{b}}$} \\
\hline & & & & & & $\mathbf{L L}$ & UL & & & & \\
\hline $\begin{array}{l}\text { T1 } \\
\text { T2 }\end{array}$ & $\begin{array}{l}6 \\
3\end{array}$ & $\begin{array}{r}11 \\
5\end{array}$ & $\begin{array}{r}179 \\
80\end{array}$ & $\begin{array}{l}\mathrm{R} \\
\mathrm{R}\end{array}$ & $\begin{array}{l}2.55^{*} \\
3.44^{* *}\end{array}$ & $\begin{array}{l}1.61 \\
1.25\end{array}$ & $\begin{array}{l}3.5 \\
5.64\end{array}$ & $\begin{array}{l}117.8^{*} \\
86.11^{*}\end{array}$ & $\begin{array}{l}91.51 \\
95.4\end{array}$ & $\begin{array}{l}+7.5 \mathrm{~mm} \mathrm{Hg} \\
+10.1 \mathrm{~mm} \mathrm{Hg} \mathrm{fr}\end{array}$ & $\begin{array}{l}+2.6 \mathrm{~mm} \mathrm{Hg} \text { to }+19.8 \mathrm{~mm} \mathrm{Hg} \\
+10.4 \mathrm{~mm} \mathrm{Hg} \text { to }+38.0 \mathrm{~mm} \mathrm{Hg}\end{array}$ \\
\hline
\end{tabular}

Abbreviations: CI, confidence interval; $d$, standardized mean difference; $I^{2}$, heterogeneity statistic; IOP, intraocular pressure; $k$, comparisons; LL, lower limit; Q, Cochrane Q; R, random effects; $s$, studies; T1, after induction of anesthesia to 0 to 10 minutes of prone position; T2, 0 to 10 minutes of prone position to the end of prone position; $\mathrm{UL}=$ upper limit

$* P \leq .001$

$* * P=.002$.

${ }^{a}$ Mean effect sizes were converted to the metric used to measure IOP (ie, $\mathrm{mm} \mathrm{Hg}$ ) following the procedures described by Lipsey and Wilson. ${ }^{58}$

${ }^{\mathrm{b}}$ In $95 \%$ of all populations, the true effect size will fall within this range.

no treatment. Czorlich et $\mathrm{al}^{67}$ reported 1 corneal irritation in a single eye requiring no treatment. Hunt et $a l^{68}$ reported 4 patients with facial swelling ( 2 with minor periorbital swelling, 2 with severe facial swelling). There was no relationship between the severity of facial swelling and increased IOP.

\section{DISCUSSION}

The results of this systematic review and analysis have shown that IOP increases significantly for adult patients undergoing surgery in the prone position. As shown in Figure 2, if an individual had a baseline IOP of $13.3 \mathrm{~mm} \mathrm{Hg}$ after induction of anesthesia (as indicated by the pooled mean calculated for T0), by the end of prone position, IOP could increase to $30.9 \mathrm{~mm} \mathrm{Hg}(13.3 \mathrm{~mm} \mathrm{Hg}+$ $7.5 \mathrm{~mm} \mathrm{Hg}+10.1 \mathrm{~mm} \mathrm{Hg}=30.9 \mathrm{~mm} \mathrm{Hg}$ ). Based on the upper limits of the prediction intervals, IOP

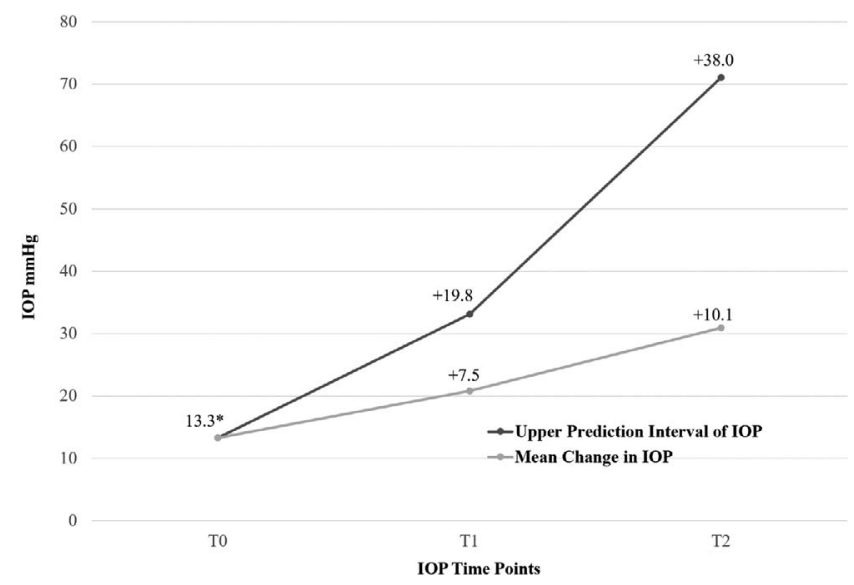

Figure 2. Magnitude of change in intraocular pressure and upper prediction intervals for T0 (induction of anesthesia) through T2 (0 to 10 minutes of prone position to the end of prone position). IOP indicates intraocular pressure; $\mathrm{T}$, time point. Intraocular pressure increases significantly when the patient is placed in prone position ( $\mathrm{T} 1$ [after induction of anesthesia to 0 to 10 minutes of prone position]: $+7.5 \mathrm{~mm} \mathrm{Hg} ; P<.001)$ and continues to increase significantly until the end of prone position (T2: $+10.1 \mathrm{~mm} \mathrm{Hg} ; P=0.002)$. The upper prediction interval shows that in $95 \%$ of all populations, at the end of prone position, IOP could increase to $71.1 \mathrm{~mm} \mathrm{Hg}(13.3 \mathrm{~mm} \mathrm{Hg}+19.8 \mathrm{~mm} \mathrm{Hg}+38.0 \mathrm{~mm} \mathrm{Hg}=71.1$ $\mathrm{mm} \mathrm{Hg}) .{ }^{*}$ Pooled mean at T0. could increase to $71.1 \mathrm{~mm} \mathrm{Hg}(13.3 \mathrm{~mm} \mathrm{Hg}+19.8$ $\mathrm{mm} \mathrm{Hg}+38.0 \mathrm{~mm} \mathrm{Hg}=71.1 \mathrm{~mm} \mathrm{Hg}$ ). An IOP of $71.1 \mathrm{~mm} \mathrm{Hg}$ is more than 3 times the highest parameter of normal IOP (ie, $21 \mathrm{~mm} \mathrm{Hg}$ ).

The mean (SD) IOP for the general population has been reported as $15.5(2.5) \mathrm{mm} \mathrm{Hg} .{ }^{74}$ An IOP of $23 \mathrm{~mm} \mathrm{Hg}$ is 3 standard deviations above the reported mean (ie, $15.5 \mathrm{~mm} \mathrm{Hg}+2.5 \mathrm{~mm} \mathrm{Hg}+2.5$ $\mathrm{mm} \mathrm{Hg}+2.5 \mathrm{~mm} \mathrm{Hg}=23 \mathrm{~mm} \mathrm{Hg}$ ) and has thus been considered as a marker of abnormally elevated IOP. ${ }^{74}$ Yoshimura et $\mathrm{al}^{34}$ conducted a study to evaluate predictive factors associated with increased IOP during spine surgery in the prone position. The researchers found that a preoperative IOP of $23 \mathrm{~mm}$ $\mathrm{Hg}$ or greater was predictive of a postoperative IOP of $30 \mathrm{~mm} \mathrm{Hg}$ or greater. Riva et $\mathrm{al}^{75}$ found that the highest IOP at which the retina was able to maintain a constant blood flow was a mean (SD) of 29.6 (2) $\mathrm{mm} \mathrm{Hg}$. Pillunat et $\mathrm{al}^{76}$ found that blood flow to the optic nerve remained nearly constant until IOP reached $40 \mathrm{~mm} \mathrm{Hg}$. The researchers noted, however, that some individuals do not exhibit autoregulation, and even a very modest increase in IOP can lead to a decline in blood flow to the optic nerve.

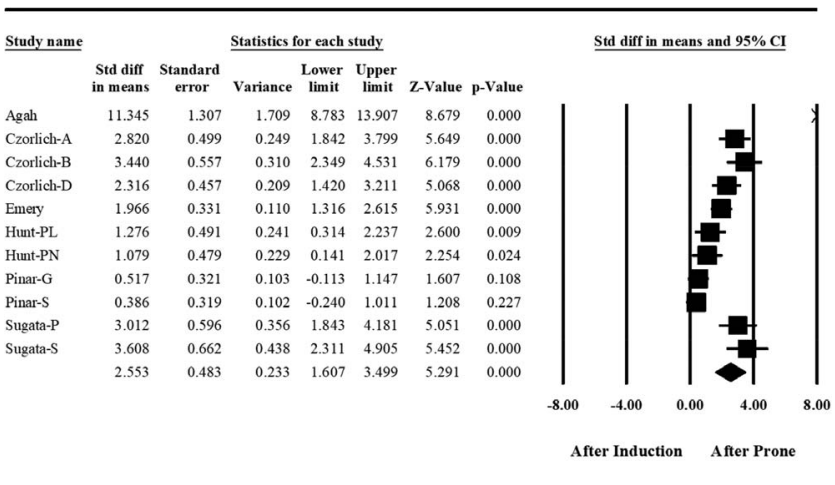

Figure 3. Forest plot of meta-analysis of T1 (after induction of anesthesia to 0 to 10 minutes of prone position). This analysis included 6 studies representing 11 participant groups $(n=179)$. Effect sizes were calculated using a random effects model. The area of each square is proportional to study weight. 


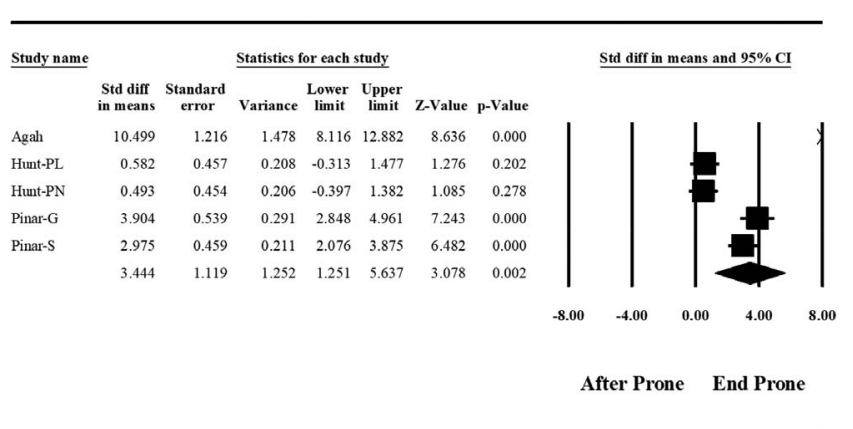

Figure 4. Forest plot of meta-analysis of T2 (0 to 10 minutes of prone position to the end of prone position). This analysis included 3 studies representing 5 participant groups $(n=80)$. Effect sizes were calculated using a random effects model. The area of each square is proportional to study weight.

\section{Implications for Practice}

Increased IOP puts the patient at risk for glaucoma, detached retina, or partial to complete vision loss. ${ }^{20,23,24}$ Intraocular pressure increases of the magnitude found in this systematic review and meta-analysis clearly demonstrate the need for implementing intraoperative interventions to mitigate the increase in IOP and reduce the potential for serious ocular complications in patients undergoing surgery in the prone position.

Positioning the patient in a 5- to 10-degree reverse Trendelenburg prone position may be a simple intervention to prevent some instances of postoperative vision loss. This position has been shown to decrease IOP in healthy volunteers ${ }^{77,78}$ and in patients undergoing spine surgery. ${ }^{1,74,79-81}$ Positioning surgical patients with the head above the heart helps reduce venous congestion in the eye and orbit and decrease intraocular and intraorbital pressure. ${ }^{25,81-83}$ Reducing the length of time the patient is in the prone position may also help to mitigate the increase in IOP. The ASA Task Force on Perioperative Visual Loss et $\mathrm{al}^{84}$ considers procedures to be prolonged when they exceed an average of 6.5 hours duration (range: 2 to 12 hours) and they suggest staging procedures when patients will be in the prone position for prolonged periods of time. Using a series of shorter procedures rather than 1 prolonged procedure may help reduce the patient's risk for postoperative vision loss; however, the risks associated with multiple surgeries may outweigh the benefits of staged procedures. ${ }^{16}$

Because IOP increases during prone position, intraoperative monitoring of IOP either continuously or at established intervals or time points (eg, after initiation of prone position, after every 60 minutes of prone position, etc.) seems prudent.

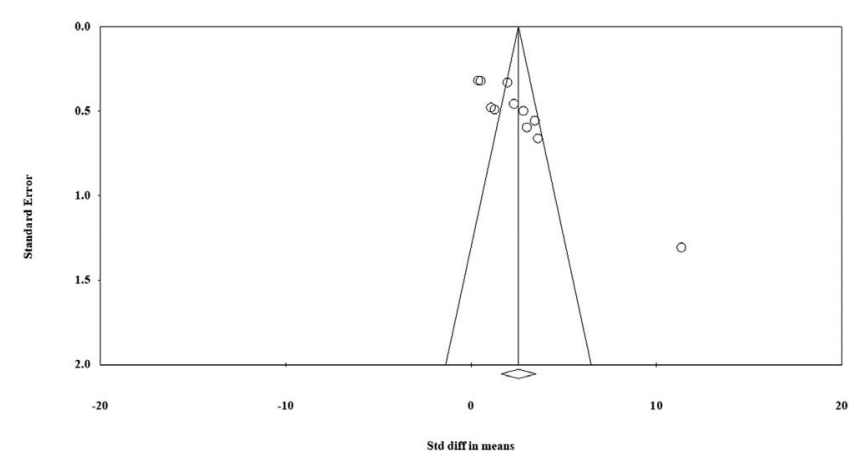

Figure 5. Funnel plot of publication bias for T1 (after induction of anesthesia to 0 to 10 minutes of prone position). Larger studies are shown at the top of the funnel. Positive smaller studies should appear at the right of the mean effect size (ie, center line). The significant Egger regression intercept for this funnel plot (bias $=9.11 ; P=.00015$ ) may be indicative of potential publication bias in the studies included in the meta-analysis for this time point. However, the Orwin fail-safe $\mathrm{N}$ is 177 , suggesting a need for 177 additional studies with an effect size of 0 before the cumulative effect would become trivial (defined as a Cohen $d$ of 0.1 ).

Yoshimura et $\mathrm{al}^{34}$ suggested that measuring IOPs after 1 hour of surgery in the prone position could provide an opportunity for implementing interventions to prevent additional increases in IOP. Eddama $^{30}$ also suggested that regular measurement of IOP during prolonged surgeries provides an opportunity for implementing a change in the patient's position when critical thresholds are reached.

Implementing periodic intraoperative position changes or rest periods (where the ocular level is above the heart) can help to reduce IOP. Molloy and Watson ${ }^{85}$ implemented a 5- to 7-minute level supine intervention after 60 minutes of steep Trendelenburg position and found there was a significant decrease in IOP.

When the patient is in the prone position, there is a risk for direct compression on the eye. ${ }^{81} \mathrm{Yu}$ et $\mathrm{al}^{86}$ found that the prone position was a precipitating factor for eye injury. Preventing direct pressure and assessing and monitoring the patient's eyes at regular intervals throughout the procedure may help to reduce the incidence of postoperative vision loss. ${ }^{12,16,82,84}$ Avoiding specific headrests or positioning devices that may increase pressure on the eye (eg, horseshoe-shaped, Wilson frame) or using skull pins or tongs to position the head may also help to prevent pressure on the orbits and reduce the risk for postoperative vision loss. ${ }^{4,5,8-10,14,19}$ Direct compression from a horseshoe-shaped head positioner has been reported as a cause of postoperative vision loss when the patient is in the prone position. ${ }^{3,5,8-10,12,19}$ In a case-controlled study of 80 patients with ischemic optic neuropathy com- 
pared with 315 matched control patients, the ASA Postoperative Visual Loss Study Group ${ }^{87}$ found that Wilson frame use was an independent risk factor for postoperative vision loss.

Administering specific medications or anesthetics may also be effective in reducing IOP or mitigating the intraoperative increase in IOP. ${ }^{69,70,88}$ Pinar et $\mathrm{al}^{69}$ found that the increase in IOP was significantly less in patients undergoing lumbar disc surgery in the prone position under spinal anesthesia compared with patients receiving general anesthesia. Sugata et $\mathrm{al}^{70}$ found that IOPs were higher in patients undergoing prone spine surgery with general anesthesia maintained with sevoflurane compared with patients receiving general anesthesia maintained with intravenous propofol. Farag et $\mathrm{al}^{88}$ found that the administration of topical brimonidine $2 \%$ helped reduce intraoperative IOP.

Another important consideration for practice is the need to evaluate whether patients undergoing surgery in the prone position should receive a preoperative ophthalmologic examination to reduce the risk for ocular injury. ${ }^{18,21,26,27,81}$ Preoperative ophthalmologic examinations may be helpful in identifying patients at risk for postoperative vision loss. Increases in IOP may be more harmful in older patients, patients with risk factors for postoperative vision loss, or in patients who are predisposed to developing diabetes or glaucoma than in younger, healthier patients. ${ }^{17,19,26,27,84}$ Patients at risk for acute angle-closure glaucoma associated with the prone position may benefit from preoperative laser iridotomy. ${ }^{26,27}$ The ASA Task Force on Perioperative Visual Loss et $\mathrm{al}^{84}$ recommend evaluating the need for preoperative ophthalmologic examination on a case-by-case basis.

\section{Implications for Future Research}

Further research relative to the magnitude of IOP increases in patients undergoing surgery in the prone position is warranted. To allow for consistent data collection, comparison, meta-analysis, and reporting, researchers of future studies should use standardized time points for measurement (ie, before induction, after induction, after change to prone position and every 60 minutes thereafter, after return to supine position, and postoperatively). Further, researchers should present data in a consistent format for each time point (ie, sample size, mean, SD).

\section{Limitations}

This systematic review and meta-analyses has several limitations. The number of included studies and participants is small $(s=9 ; \mathrm{N}=229)$. As shown in Figure 1, studies were excluded for a variety of reasons; however, 5 studies were excluded from the analyses solely because of a lack of data necessary to calculate an effect size. The researchers were contacted a minimum of 2 times to obtain missing data, but none responded. One researcher excluded participants based on $\mathrm{BMI}^{67}$; therefore, the mean value for this variable may not fully reflect the true characteristics of all adult surgical patients.

The meta-analysis examined only 2 intraoperative time points. The analysis for $\mathrm{T} 2$ reflects IOP measurements from patients in the prone position for varying lengths of time. Having data for specific time points would be preferable. This lack of data collection by researchers is likely due to the difficulty of measuring IOP with the patient in prone position. Because researchers measured IOP at varying intraoperative time points, all studies could not be included at all time points examined in the meta-analysis. Additionally, there were not enough studies included at each time point to allow for moderator analyses.

Heterogeneity was significant at both time points (T1: $I^{2}=91.5, P<.001 ; \mathrm{T} 2: I^{2}=95.4, P<.001$ ), indicating that variation across studies was substantial, potentially limiting generalizability. Notably, heterogeneity among the studies included in a meta-analysis is common and should be anticipated, not regarded as the exception. ${ }^{51}$ The significant Egger regression intercept for the funnel plot (bias $=$ $9.2 ; P=.00019)$ may also be indicative of potential publication bias in the studies included in the metaanalysis. The Egger test has low power for metaanalyses containing small to moderate numbers of studies. ${ }^{59}$ However, the Orwin fail-safe $\mathrm{N}$ is 177 , suggesting a need for 177 additional studies with an effect size of 0 before the cumulative effect would become trivial (defined as a Cohen $d$ of 0.1). With such high numbers of studies required to overturn the conclusions of the meta-analysis, the overall observed effect size can be considered robust. ${ }^{59,62}$

\section{CONCLUSION}

Intraocular pressure increases significantly between induction of anesthesia and the end of prone position. The IOP increases significantly within 10 
minutes after the patient is placed into the prone position and continues to increase significantly while the patient is in prone position. The IOP increases of the magnitude found in this systematic review and meta-analysis clearly demonstrate the need for implementing interventions to mitigate the increase in IOP and reduce the risk for postoperative vision loss and other ocular complications in patients undergoing surgery in the prone position. Implementing the recommended interventions presents no harm to the patient, but may benefit the patient by reducing the risk for increased IOP that may lead to glaucoma, detached retina, or postoperative vision loss.

\section{ACKNOWLEDGMENTS}

The author wishes to thank Jo-Ana D. Chase, PhD, APRN-BC, Vicki S. Conn, PhD, RN, FAAN, Deidre D. Wipke-Tevis, PhD, RN, Sinclair School of Nursing, and Christine Proulx, PhD, Department of Human Development and Family Science, University of Missouri, Columbia, for their support and guidance in developing this systematic review and meta-analysis; Marie $\mathrm{Ba}-$ shaw, DNP, RN, NEA-BC, Department of Nursing, Hartwick College, Oneonta, New York, for her assistance in providing independent review and appraisal of the studies included in this systematic review and meta-analysis; Danielle Karasko, MSN, CRNP, PhD candidate, Sinclair School of Nursing, University of Missouri, Columbia, and Philadelphia Children's Hospital, Pennsylvania, for her assistance in providing independent coding of the studies included in this systematic review and metaanalysis; and Rebecca Graves, Health Science Library, University of Missouri, Columbia, for her assistance with developing effective search terms and strategies.

\section{REFERENCES}

1. Emery SE, Daffner SD, France JC, et al. Effect of head position on intraocular pressure during lumbar spine fusion: a randomized, prospective study. J Bone Joint Surg Am. 2015;97(22):1817-1823.

2. Lee LA, Newman N. Postoperative visual loss after anesthesia for nonocular surgery. UpToDate. 2018. https:// www.uptodate.com/contents/postoperative-visual-loss-after-an esthesia-for-nonocular-surgery. Accessed December 24, 2018.

3. Abraham M, Sakhuja N, Sinha S, Rastogi S. Unilateral visual loss after cervical spine surgery. J Neurosurg Anesthesiol. 2003;15(4):319-322.
4. Asok T, Aziz S, Faisal HA, Tan AK, Mallika PS. Central retinal artery occlusion and opthalmoplegia following spine surgery in the prone position. Med J Malaysia. 2009;64(4):323324.

5. Bekar A, Türeyen K, Aksoy K. Unilateral blindness due to patient positioning during cervical syringomyelia surgery: unilateral blindness after prone positioning. $J$ Neurosurg Anesthesiol. 1996;8(3): 227-229.

6. Dilger JA, Tétzlaff JE, Bell GR, Kosmorsky GS, Agnor RC, O'Hara JF Jr. Ischaemic optic neuropathy after spinal fusion. Can J Anaesth. 1998;45(1):63-66.

7. Goni V, Tripathy SK, Goyal T, Tamuk T, Panda BB, Shashidhar BK. Cortical blindness following spinal surgery: very rare cause of perioperative vision loss. Asian Spine J. 2012;6(4):287-290.

8. Grossman W, Ward, WT. Central retinal artery occlusion after scoliosis surgery with a horseshoe headrest: case report and literature review. Spine. 1993;18(9):1226-1228.

9. Hollenhorst RW, Svien HJ, Benoit CF. Unilateral blindness occurring during anesthesia for neurosurgical operations. AMA Arch Ophthalmol. 1954;52(6):819-830.

10. Hoski JJ, Eismont FJ, Green BA. Blindness as a complication of intraoperative positioning: a case report. $J$ Bone Joint Surg. 1993;75(8):1231-1232.

11. Katz DM, Trobe JD, Cornblath WT, Kline LB. Ischemic optic neuropathy after lumbar spine surgery. Arch Ophthalmol. 1994;112(7):925-931.

12. Locastro A, Novak KD, Biglan AW. Central retinal artery occlusion in a child after general anesthesia. Am J Ophthalmol. 1991;112(1):91-92.

13. Manfredini M, Ferrante R, Gildone A, Massari L. Unilateral blindness as a complication of intraoperative positioning for cervical spinal surgery. J Spine Disord. 2000;13(3):271-272.

14. Quraishi NA, Wolinsky JP, Gokaslan ZL. Transient bilateral post-operative visual loss in spinal surgery. Eur Spine J. 2012;21(Suppl 4):S495-S498.

15. Reddy A, Foroozan R, Edmond JC, Hinckley LK. Dilated superior ophthalmic veins and posterior ischemic optic neuropathy after prolonged spine surgery. $J$ Neuroophthalmol. 2008;28(4):327-328.

16. Shifa J, Abebe W, Bekele N, Habte D. A case of bilateral visual loss after spinal cord surgery. Pan Afr Med J. 2016;23:119.

17. Stang-Veldhouse KN, Yeu E, Rothenberg DM, Mizzen, TR. Unusual presentation of perioperative ischemic optic neuropathy following major spine surgery. J Clin Anesth. 2010;22(1):52-55.

18. West J, Askin G, Clarke M, Vernon SA. Loss of vision in one eye following scoliosis surgery. $\mathrm{Br} J$ Ophthalmol. 1990;74(4):243-244.

19. Wolfe SW, Lospinuso MF, Burke SW. Unilateral blindness as a complication of patient positioning for spinal surgery: a case report. Spine. 1992;17(5):600-605.

20. Kwee MM, Ho YH, Rozen WM. The prone position during surgery and its complications: a systematic review and evidence-based guidelines. Int Surg. 2015;100(2):292-303.

21. Akhaddar A, Boucetta M. Subconjunctival hemorrhage as a complication of intraoperative positioning for lumbar spinal surgery. Spine J. 2012;12(3);274. 
22. Russell DJ, Dutton JJ. Bilateral spontaneous subperiosteal orbital hemorrhages following endoscopic retrograde cholangiopancreatography. Ophthalmic Plast Reconstr Surg. 2011;27(3):e49-e50.

23. Amorim Correa JL Acioly MA. The enigma of orbital compartment syndrome after lumbar spine surgery in the prone position: case report and literature review. World Neurosurg. 2018;110:309-3147.

24. Leibovitch I, Casson R, Laforest C, Selva D. Ischemic orbital compartment syndrome as a complication of spinal surgery in the prone position. Ophthalmology. 2006;113(1):105108.

25. Kamel I, Barnette R. Positioning patients for spine surgery: avoiding uncommon position-related complications. World J Orthop. 2014;5(4):425-443.

26. Singer MS, Salim S. Bilateral acute angle-closure glaucoma as a complication of facedown spine surgery. Spine J. 2010;10(9):e7-e9.

27. Stewart RJ, Landy DC, Lee MJ. Unlateral acute angleclosure glaucoma after lumbar spine surgery: a case report and systematic review of the literature. Spine. 2016;41(5):E297E299.

28. Guillaume JE, Gowreesunker P. Horner's syndrome in the prone position: a case report. Acta Anaesthesiol Belg. 2013;64(3):119-121.

29. Agah M, Ghasemi M, Roodneshin F, Radpay B, Moradian S. Prone position in percutaneous nephrolithotomy and postoperative visual loss. Urol J. 2011;8(3):191-196.

30. Eddama M. Re: raised intraocular pressure and perioperative visual loss in laparoscopic colorectal surgery: a catastrophe waiting to happen? A systematic review of evidence from other surgical specialties. Tech Coloproctol. 2013;17(2):247.

31. Kendrick H. Post-operative vision loss (POVL) following surgical procedures. J Anesth Clin Res. 2012;3(1):184.

32. Pinkney TD, King AJ, Walter C, Wilson TR, MaxwellArmstrong C, Acheson AG. Raised intraocular pressure (IOP) and perioperative visual loss in laparoscopic colorectal surgery: a catastrophe waiting to happen? A systematic review of evidence from other surgical specialties. Tech Coloproctol. 2012;16(5):331-335.

33. Szmuk P, Steiner JW, Pop RB, et al. Intraocular pressure in pediatric patients during prone surgery. Anesth Analg. 2012;116(6):1309-1313.

34. Yoshimura K, Hayashi H, Tanaka Y, Nomura Y, Kawaguchi M. Evaluation of predictive factors associated with increased intraocular pressure during prone position spine surgery. J Anesth. 2015;29(2):170-174.

35. Nuzzi R, Tridico R. Ocular complications in laparoscopic surgery: review of existing literature and possible prevention and treatment. Semin Ophthalmol. 2016;31(6):584592.

36. American Academy of Ophthalmology. Intraocular pressure. 2018. https://www.aao.org/bcscsnippetdetail.as px?id=f010bbf6-3f3e-486b-b5cd-0ad86ddb9d74. Accessed December 24, 2018.

37. Weinreb RN, Khaw PT. Primary open-angle glaucoma. Lancet. 2004;363(9422):1711-1720.

38. Stambough JL, Dolan D, Wener R, Godfrey E. Ophthalmologic complications associated with prone position- ing in spine surgery. J Am Acad Orthop Surg. 2007;15(3):156165.

39. Kan KM, Brown SE, Gainsburg DM. Ocular complications in robotic-assisted prostatectomy: a review of pathophysiology and prevention. Minerva Anestesiol. 2015;81(5):557566.

40. Newman NJ. Perioperative visual loss after nonocular surgeries. Am J Ophthalmol. 2008;145(4):604-610.

41. Boyd K. What is ischemic optic neuropathy? https:// www.aao.org/eye-health/diseases/what-is-ischemic-optic-neu ropathy. Accessed December 24, 2018.

42. Hayreh SS. Blood flow in the optic nerve head and factors that may influence it. Prog Retin Eye Res. 2001;20(5):595-624.

43. Gkegkes ID, Karydis A, Tyritzis SI, Iavazzo C. Ocular complications in robotic surgery. Int $J$ Med Robot. 2015;11(3):269-274.

44. Li A, Swinney C, Veeravagu A, Bhatti I, Ratliff J. Postoperative visual loss following lumbar spine surgery: a review of risk factors. World Neurosurg. 2015;84(6):2010-2021.

45. Freshcoln M, Diehl MR. Repositioning during robotic procedures to prevent postoperative visual loss. OR Nurse. 2014;8(4):36-41.

46. Ghomi A. Robotics in practice: new angles on safer positioning. Contemp OB/GYN. 2012;57(10):26-37.

47. Patil CG, Lad EM, Lad SP, Ho C, Boakye M. Visual loss after spine surgery: a population-based study. Spine. 2008;33(13):1491-1496.

48. Berg KT, Harrison AR, Lee MS. Perioperative visual loss in ocular and nonocular surgery. Clin Ophthalmol. 2010;4:531-546.

49. Shen Y, Drum M, Roth S. The prevalence of perioperative visual loss in the United States: a 10-year study from 1996 to 2005 of spinal, orthopedic, cardiac, and general surgery. Anesth Analg. 2009;109(5):1534-1545.

50. Nuri Deniz M Erakgün A Sertöz N Yilmaz SG, Ateş H Erhan E. The effect of head rotation on intraocular pressure in prone position: a randomized trial. Braz $J$ Anesthesiol. 2013;63(2):209-212.

51. Berlin JA. Invited commentary: benefits of heterogeneity in meta-analysis of data from epidemiological studies. Am J Epidemiol. 1995;142(4):465-468.

52. Thompson SG. Why sources of heterogeneity in metaanalysis should be investigated. BMJ. 1994;309(6965):13511355.

53. Moher D, Liberati A, Tetzlaff J, Altman DG, PRISMA Group. Preferred reporting items for systematic reviews and meta-analyses: The PRISMA statement. PLoS Med. 2009;6(7):e1000097.

54. Association of periOperative Registered Nurses. Research Evidence Appraisal Tool - Study. https://www.aorn.org/ guidelines/about-aorn-guidelines/evidence-rating. 2015. Accessed March 6, 2020.

55. Borenstein M, Hedges LV, Higgins J, Rothstein $H$. Comprehensive Meta-Analysis. 2018. https://www.meta-analy sis.com. Accessed December 24, 2018.

56. Cohen JA. A power primer. Psychol Bull. 1992;12(1):155-159.

57. Borenstein M, Hedges LV, Higgins J, Rothstein $\mathrm{H}$. Fixed-effect versus random-effects models. In: Introduction to 
Meta-Analysis. West Sussex, UK: John Wiley \& Sons, Ltd; 2009:77-86.

58. Lipsey M, Wilson D. Interpreting and using metaanalysis results. In: Bickman L, Rog DJ, eds. Practical MetaAnalysis: Applied Social Research. Vol 49. Thousand Oaks, CA: Sage; 2001:146-168.

59. Sutton AJ. Publication bias. In: Cooper H, Hedges LV, Valentine JC, eds. The Handbook of Research Synthesis and Meta-Analysis. 2nd ed. New York, NY: Russell Sage Foundation; 2009:435-452.

60. Egger M, Smith GD, Schneider M, Minder CE. Bias in meta-analysis detected by a simple, graphical test. BMJ Clin Res. 1997;315(7109):629-634.

61. Sterne JAC, Egger M, Moher D, eds. Chapter 10: Addressing reporting biases. In: Deeks JJ, Higgins JPT, eds. Cochrane Handbook for Systematic Reviews of Interventions. Version 5.1.0 [updated March 2011]. The Cochrane Collaboration;2011:10.1-10.6. www.handbook.cochrane.org. Accessed December 24, 2018.

62. Orwin RG. A fail-safe $N$ for effect size in meta-analysis. J Educ Stat. 1983;8(2):157-159.

63. Deeks JJ, Higgins JPT, Altman, DG. Chapter 9: analyzing data and undertaking meta-analysis. In: Deeks JJ, Higgins JPT, eds. Cochrane Handbook for Systematic Reviews of Interventions Version 5.1.0 [Updated March 2011]. The Cochrane Collaboration;2011:9.1-9.9. www.handbook.co chrane.org. Accessed December 24, 2018.

64. Higgins JPT, Thompson SG, Deeks JJ, Altman DG. Measuring inconsistency in meta-analysis. $B M J$. 2003;327(7414):557-560.

65. Borenstein $M$, Hedges LV, Higgins $J$, Rothstein $H$. Identifying and quantifying heterogeneity. In: Introduction to Meta-analysis. West Sussex, UK: John Wiley \& Sons, Ltd; 2009:107-125.

66. Borenstein M, Hedges LV, Higgins J, Rothstein H. Prediction intervals. In: Introduction to Meta-analysis. West Sussex, UK: John Wiley \& Sons, Ltd; 2009:127-133.

67. Czorlich P, Krätzig T, Kluge N, et al. Intraocular pressure during neurosurgical procedures in context of head position and loss of cerebrospinal fluid. $J$ Neurosurg. 2019;131(1):271-280. doi: 10.3171/2018.3.JNS173098.

68. Hunt K, Bajekal R, Calder I, Meacher R, Eliahoo J, Acheson JF. Changes in intraocular pressure in anesthetized prone patients. J Neurosurg Anesthesiol. 2004;16(4):287-290.

69. Pinar HU, Kaşdoğan ZEA, Başaran B, Çöven I, Karaca Ö, Doğan R. The effect of spinal versus general anesthesia on intraocular pressure in lumbar disc surgery in the prone position: a randomized controlled trial. $J$ Clin Anesth. 2018;46:54-58.

70. Sugata A, Hayashi H, Kawaguchi M, Hasuwa K, Nomura Y, Furuya H. Changes in intraocular pressure during prone spine surgery under propofol and sevoflurane anesthesia. J Neurosurg Anesth. 2012;24(2):152-156.

71. Centers for Disease Control and Prevention. Defining adult overweight and obesity. Updated 2016. https://www.cdc. gov/obesity/adult/defining.html. Accessed December 24, 2018.

72. American Society of Anesthesiologists. ASA Physical Status Classification System. Updated 2018. https://www. asahq.org/standards-and-guidelines/asa-physical-status-classifi cation-system. Accessed December 24, 2018.
73. Cheng MA, Todorov A, Tempelhoff R, McHugh R, Chowder CM, Lauryssen $\mathrm{C}$. The effect of prone positioning on intraocular pressure in anesthetized patients. Anesthesiology. 2001;95(6):1351-1355.

74. Carey TW, Shaw KA, Weber ML, DeVine JG. Effect of the degree of reverse Trendelenburg position on intraocular pressure during prone spine surgery: a randomized controlled trial. Spine J. 2014;14(9):2118-2126.

75. Riva CE, Sinclair SH, Grunwald JE. Autoregulation of retinal circulation in response to decrease of perfusion pressure. Invest Ophthalmol Vis Sci. 1981;21(1):34-38.

76. Pillunat LE, Anderson DR, Knighton RW, Joos KM, Feuer WJ. Autoregulation of human optic nerve head circulation in response to increased intraocular pressure. Exp Eye Res. 1997;64(5):727-744.

77. Ozcan MS, Praetel C, Bhatti MT, Gravenstein N, Mahla $\mathrm{ME}$, Seubert $\mathrm{CN}$. The effect of body inclination during prone positioning on intraocular pressure in awake volunteers: a comparison of two operating tables. Anesth Analg. 2004;99(4):1152-1158.

78. Walick KS, Kragh JE, Ward JA, Crawford JJ. Changes in intraocular pressure due to surgical positioning. Spine. 2007;32(23):2591-2595.

79. Fukui K, Tempelhoff R, Cheng MA. Intraocular pressure during prone position surgery: effects of time and head elevation [abstract]. J Neurosurg Anesthesiol. 2005;17(4):251.

80. Fukui K, Ahmad M, McHugh T, Tempelhoff R, Cheng MA. The effect of head elevation on intraocular pressure in anesthetized patients undergoing prone position spine surgery [abstract]. J Neurosurg Anesthesiol. 2004;16(4):358.

81. Bonnaig N, Dailey S, Archdeacon M. Proper patient positioning and complication prevention in orthopaedic surgery. J Bone Joint Surg Am. 2014;96(13):1135-1140.

82. Nickels TJ, Manlapaz MR, Farag E. Perioperative visual loss after spine surgery. World J Orthop. 2014;5(2):100-106.

83. Grant GP, Szirth BC, Bennett HL, et al. Effects of prone and reverse Trendelenburg positioning on ocular parameters. Anesthesiology. 2010;112(1):57-65.

84. American Society of Anesthesiologists Task Force on Perioperative Visual Loss, North American Neuro-Ophthalmology Society, Society for Neuroscience in Anesthesiology and Critical Care. Practice advisory for perioperative visual loss associated with spine surgery. Anesthesiology. 2019;130(1):1230 .

85. Molloy BL, Watson C. A comparative assessment of intraocular pressure in prolonged steep Trendelenburg position versus level supine position intervention. J Anesth Clin Sci. 2012. http://www.hoajonline.com/journals/pdf/2049-9752-1-9. pdf. Accessed December 24, 2018.

86. Yu HD, Chou AH, Yang MW, Chang CJ. An analysis of perioperative eye injuries after nonocular surgery. Acta Anaesthesiol Taiwanica. 2010;48(3):122-129.

87. American Society of Anesthesiologists Postoperative Visual Loss Study Group. Risk factors associated with ischemic optic neuropathy after spinal fusion surgery. Anesthesiology. 2012;116(1):15-24.

88. Farag E, Sessler DI, Kovaci, B, et al. Effects of crystalloid versus colloid and the $\alpha-2$ agonist brimonidine versus placebo on intraocular pressure during prone spine 
surgery: a factorial randomized trial. Anesthesiology. 2012;116(4):807-815.

Disclosures and COI: Dr Van Wicklin has no declared affiliation that could be perceived as posing a potential conflict of interest in the publication of this article.

Corresponding Author: Sharon Ann Van Wicklin, PhD, RN, Perioperative and Legal Nurse Consultant, 8256 South Shawnee Street, Aurora,
CO 80016. Phone: (615) 260-6231; Email: SharonVWRN@aol.com.

Published 30 April 2020

This manuscript is generously published free of charge by ISASS, the International Society for the Advancement of Spine Surgery. Copyright (C) 2020 ISASS. To see more or order reprints or permissions, see http://ijssurgery.com. 